\title{
Performance of high-strength concrete one-way slabs with embedded BFRP bar reinforcement
}

\author{
Qasim M. Shakir
}

Civil Engineering Department, College of Engineering, University of Kufa, Iraq

ARTICLE INFO

ARTICLE HISTORY:

Received: 05 May 2020

Revised: 09 July 0000

Accepted: 10 July 2020

Published: 15 July 2020

\section{KEYWORDS:}

BFRP bars, continuous RC slabs, tension-stiffening, elasticplastic, toughness

\begin{abstract}
A B S T R A C T
In this paper, a theoretical study has been concluded using ANSYS-15 software to investigate the performance of reinforced concrete one-way slabs with embedded basalt fibre reinforced polymer (BFRP) bars under monotonic loads. Six slabs have been considered, two were simply supported, and four were continuous each with two-span. Several parameters have been studied, such as continuity condition, reinforcement ratio, the position of the reinforcement and the effect of replacement basalt bars by steel bars. It is found that the finite element analysis (FEA) agree with experimental results in a range of $1 \%-9 \%$ in deflection compared with the maximum difference of ACI440 committee of $49 \%$. For simply supported slabs, it is found that increasing the reinforcement from $0.2 \%$ to $0.5 \%$ resulted in increased capacity by $86 \%$. For continuous slabs, it is observed that increasing the reinforcement for top and bottom from $0.2 \%$ to $0.5 \%$ resulted in increased capacity by $60 \%$ while the maximum deflection is reduced by 56\%. Moreover, it is found that with an efficient distribution of bars a slab with a reinforcement ratio of $0.7 \%$, the load capacity is improved by $12.5 \%$ and a reduction in maximum deflection $46 \%$. Furthermore, it is found that for simply supported slabs, it is better to use higher ratios of BFRP reinforcement, $0.5 \%$ instead of $0.2 \%$ due to a good improvement in capacity. Regarding dissipation in energy, it is found that the difference in predicting toughness by FEA by ANSYS was 1\% - 15\% for simply supported slabs while for continuous slabs the dissipation in energy was in the range of $20 \%$ - 50\% compared with experimental results.
\end{abstract}

\section{INTRODUCTION}

In the last few decades, polymer composites as glass, carbon, and aramid bars have been adopted as an efficient alternate choice of the steel reinforcing bars which are prone to the corrosion and may cause deterioration of concrete elements and in some situations, the collapse of the structure. Polymer composites have some merits over steel including; high resistance to tension, having good stiffness/weight ratios and being good resistant to corrosive and aggressive environments. Furthermore, thermally controlled, provide good performance in damping and being inactive against electromagnetic fields (Issa et al., 2016).

Such composites have been used as main reinforcement and as stirrups in some concrete infrastructures such as bridges, substructure members as footings, slabs, retaining walls that may be prone to corrosion. Recently, fibres made from basalt have been utilized in introducing a new version of FRP composite, called as basalt fibre reinforced polymers (BFRP). The most common figures of such composite are fibres and bars.
Basalt fibres are environmentally friendly as they have no-harmful effects, resistant to corrosion, not affected by magnetic fields, less susceptible to heat with good insulation properties (Marlena \& Bartłomiej, 2014; Meng et al., 2015). It was reported that the ultimate tensile stress of the basalt fibres is about twice that of $\mathrm{E}$ glass fibres with a modulus of elasticity of about 15\% - 30\% higher (Ramakrtshnan \& Panchalan, 2012). Based on these merits, it can be widely used in different structures such as barriers of the highways, offshore structures and slabs for bridges. Thus, BFRP bars provided suitable substitution to the classical FRP bars (El Refai 2015; Ge et al., 2015). Several studies have been conducted to investigate the performance of one-way slabs reinforced with basalt bars. Neela (2010) investigated experimentally the response of concrete slabs reinforced with BFRP bars included polypropylene fibres with two values of volume fraction, namely are $1.0 \%$ and $0.5 \%$. It was reported that there are some increments in failure load, the compressive strain of concrete and tensile strain of bars 
with the polypropylene fibre. In contrast, some reduction in deflections was recorded when adding the fibres to the concrete. Ashraf (2014) studied the performance the simply supported and continuous concrete slabs with embedded BFRP and carbon fibre reinforced polymer (CFRP) bars. For continuous slabs, it has been concluded that adopting a higher reinforcement ratio in the bottom mid-span region is more influential than the top middle support in improving the ultimate load and reduction of the mid-span deflections. Mahroug et al. (2014) tested two simply supported, and four continuous concrete slabs reinforced two with embedded basalt fibre reinforced polymer BFRP bars. The results have been compared with the predicted values by equations of ACI440 committee. It was found that the continuous supported BFRP reinforced concrete slabs exhibited larger deflections and wider cracks than those reinforced with steel. Elgabbas (2016) investigated experimentally the short- and long-term performance of concrete beams and slabs of the bridge deck included BFRP bars. Results showed that the BFRP bars had good mechanical behaviour as glass fibre reinforced polymer (GFRP) bars.

The response of the continuous reinforced concrete slabs with embedded hybrid steel-basalt bars have been investigated by Akiel (2016). It was concluded that using BFRP bars of hogging/sagging $=2.0$, resulted in increasing the capacity of the over-reinforced and under-reinforced slabs by $18 \%$ and $30 \%$, respectively. Furthermore, it was observed that the deflection at service loading stage for slabs, including both types of bars was reduced by half relative to that with BFRP bars only. Whereas crack widths in the hogging zones were reduced by $57 \%$ and $78 \%$ of the over-reinforced and under-reinforced sections respectively compared to that with BFRP bars only. Zhou et al. (2018) used the nonlinear finite element software ABAQUS 6.10 to study the response of basalt fibre-reinforced polymer BFRP self-compacting concrete deck slabs. The results revealed the adopted model may predict the response with acceptable limits and corresponding information within the results of the field test have been noticed. Rihan (2018) conducted an experimental and analytical investigation of the general response of basalt fibre reinforced concrete (BFRC) one-way slabs including embedded basalt FRP bars and glass FRP bars. Several variables have been considered, including the reinforcement ratio and the basalt macro-fibre volume fraction. Some improvement during the moments recorded at cracking and failure stages, mid-span deflection and ductility index have been noticed with increasing content of basalt macro-fibres (BMF) and the ratio of the main reinforcement. An experimental and analytical investigation on BMF reinforced concrete one-way slab system reinforced with BFRP or GFRP bars has been achieved by Attia et al. (2019). It was obtained that using $\mathrm{BMF}$ of fibre content $(\mathrm{Vf})=2 \%$ resulted in enhancing both of the compressive strength and rupture modulus of concrete by $10 \%$ and $37 \%$, respectively. Furthermore, an improvement in the cracking load in the range of $46 \%-$
93\% was obtained. Regarding the flexural capacity, enhancement of $41 \%$ and $33 \%$ were obtained when using BFRP- and GFRP-bars, respectively in reinforced concrete slabs.

In the last few years, some researches have reported on the behaviour of concrete slabs/beams containing embedded FRP bars with simple spans. But very little studies were achieved on the performance of continuous concrete slabs reinforced included BFRP bars. Thus, this work adopted the finite element approach using ANSYS software (SAS, 2013) to study the performance of the concrete one-way slabs with embedded BFRP bars as reinforcing elements instead of the conventionally used deformed steel bars. In addition, the effect of the gradual substitution of BFRP bars with steel bars on the load-deflection curve is investigated in this manuscript.

\section{METHODOLOGY}

\subsection{The geometry of tested slabs}

The one-way reinforced concrete slabs that have been considered in the present study were tested experimentally by Mahroug et al. (2014). The tested slabs consist of six specimens; two are simply supported slabs, as shown in Fig. 1 and Fig. 4 which are continuous with different ratios of BFRP bars as shown in Fig. 2. The thickness of all slabs is $150 \mathrm{~mm}$ while the width is $500 \mathrm{~mm}$ with the span between every two successive supports is $2000 \mathrm{~mm}$ with the cover of reinforcement being $25 \mathrm{~mm}$. The designations of slabs, concrete properties are listed in Table 1, while the material properties of FRP and steel reinforcing bars are listed in Table 2. Also, Mahroug et al. analysed the tested slabs using the ACI440 committee method to achieve a comparison between the results recorded experimentally and those obtained theoretically.

Table 1. Characteristics of reinforcement and concrete slabs (Mahroug et al., 2014)

\begin{tabular}{|c|c|c|c|c|c|c|}
\hline & \multicolumn{4}{|c|}{ Reinforcing bars } & \multirow{2}{*}{\multicolumn{2}{|c|}{$\mathrm{N} / \mathrm{mm}^{2}$}} \\
\hline & \multicolumn{2}{|c|}{$\begin{array}{c}\text { Mid-span } \\
\text { (Bottom face) }\end{array}$} & \multicolumn{2}{|c|}{$\begin{array}{l}\text { Interior support } \\
\text { (Top face) }\end{array}$} & & \\
\hline Slab & No. & Dia.(mm) & No. & Dia.(mm) & $\left(f_{c u}\right)$ & $f_{t}$ \\
\hline SU & 3 &  & ---- & ---- & 51.2 & 4.5 \\
\hline SO & 5 & 10 & ---- & --- & 55.0 & 4.7 \\
\hline $\mathrm{COO}$ & J & 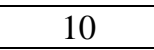 & 5 & 10 & 52.3 & 4.1 \\
\hline COU & 5 & 10 & 3 & 0 & 53.7 & 4.3 \\
\hline CUO & 3 & 8 & 5 & 10 & 56.2 & 4.4 \\
\hline CUU & 3 & 8 & 3 & 8 & 53.7 & 4.2 \\
\hline
\end{tabular}

S: Simple span; U: Under-reinforced; O: Over-reinforced; $\mathrm{C}$ : Continuous beam 

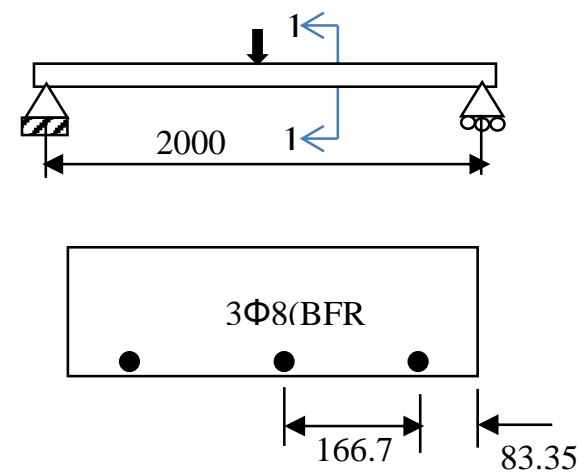

Section 1-1, SU

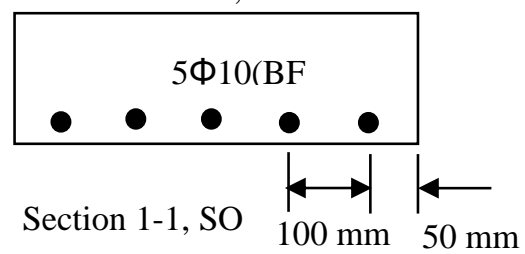

Fig. 1. Details of the simply supported slabs (Mahroug et al., 2014)

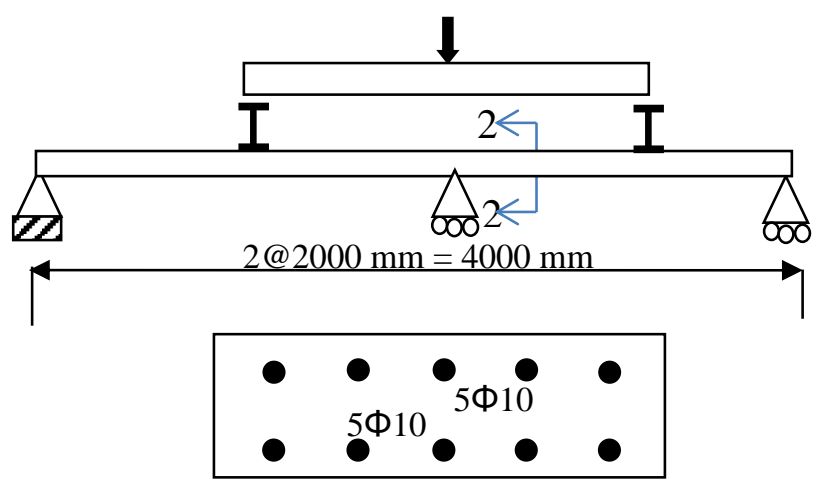

Section 2-2, COO



Section 2-2, CUU

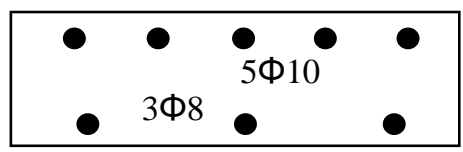

Section 2-2, CUO

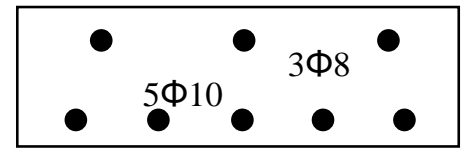

Section 2-2, COU

Fig. 2. Details of the continuous slabs (Mahroug et al., 2014)
Table 2. Properties of BFRP and steel reinforcing bars (Mahroug et al., 2014)

\begin{tabular}{|l|c|c|c|c|c|}
\hline $\begin{array}{c}\text { Bar } \\
\text { type }\end{array}$ & $\begin{array}{c}\text { Dia. } \\
(\mathbf{m m})\end{array}$ & $\begin{array}{c}\mathbf{E} \\
(\mathbf{G P a})\end{array}$ & $\begin{array}{c}f_{u} \\
(\mathbf{M P a})\end{array}$ & $\varepsilon_{u}$ & $\begin{array}{c}f_{y} \\
(\mathbf{M P a})\end{array}$ \\
\hline BFRP & 8 & 50 & 1250 & 0.025 & ----- \\
\hline BFRP & 10 & 50 & 1350 & 0.027 & ---- \\
\hline Steel & 10 & 200 & 645 & & 575 \\
\hline
\end{tabular}

\subsection{Material properties}

\subsubsection{Concrete}

An elastic-plastic work-hardening model presenting the compressive strength followed by a perfectly plastic response up to the instant of crushing is adopted to represent the compressive behaviour of the concrete. Such behaviour is shown in Fig. 3a and it can be expressed using the following relations:

$$
\begin{aligned}
& f_{c}=E \varepsilon_{c} \text { for } 0 \leq \varepsilon \leq \varepsilon_{1} \\
& f_{c}=\frac{\varepsilon E_{c}}{1+\left(\varepsilon / \varepsilon_{0}\right)^{2}} \text { for } \varepsilon_{1} \leq \varepsilon \leq \varepsilon_{0}
\end{aligned}
$$

(Wolanski, 2004)

$$
\begin{aligned}
& f_{c}=f_{c}^{\prime} \quad \text { for } \varepsilon_{0} \leq \varepsilon \leq \varepsilon_{u} \\
& \text { and } \\
& \varepsilon_{1}=0.3 f_{c}^{\prime} / E_{c} \text { (Hooke's law) } \\
& \varepsilon_{0}=2 f_{c}^{\prime} / E_{c} \\
& f^{\prime}{ }_{c}=0.9 f_{c u} \\
& E_{c}=3.3 \sqrt{f_{c}^{\prime}}+6.9 \quad \text { (Kumar et al., 2012) }
\end{aligned}
$$

When the concrete is under tension, the stress state is represented using the tension-stiffening model shown in Fig. 3b. The initial elastic modulus is used within the elastic stage. Then, the smeared cracking approach with a degraded modulus of elasticity has been utilized to represent the spreading of cracks and the gradual weakening of the section.

\subsubsection{BFRP and steel bars}

In the present study, the stress-strain relations shown in Fig. 3c has been adopted to simulate the behaviour of reinforcing bars used in the tested slabs. For basalt bars, the behaviour is assumed elastic up to the tensile strength $\left(f_{t}\right)$. While, a bilinear stress-strain curve is adopted to simulate the steel behaviour, full bond between concrete and reinforcement bars is assumed. However, this may result in some divergence from the experimental results for large spans and lightly reinforced sections without enough embedded length. To accommodate this problem, very small values for the open crack factor for concrete is 
assigned, $(\alpha 1=0.05)$ corresponding to a value of about 0.2 is generally assumed for RC beams.

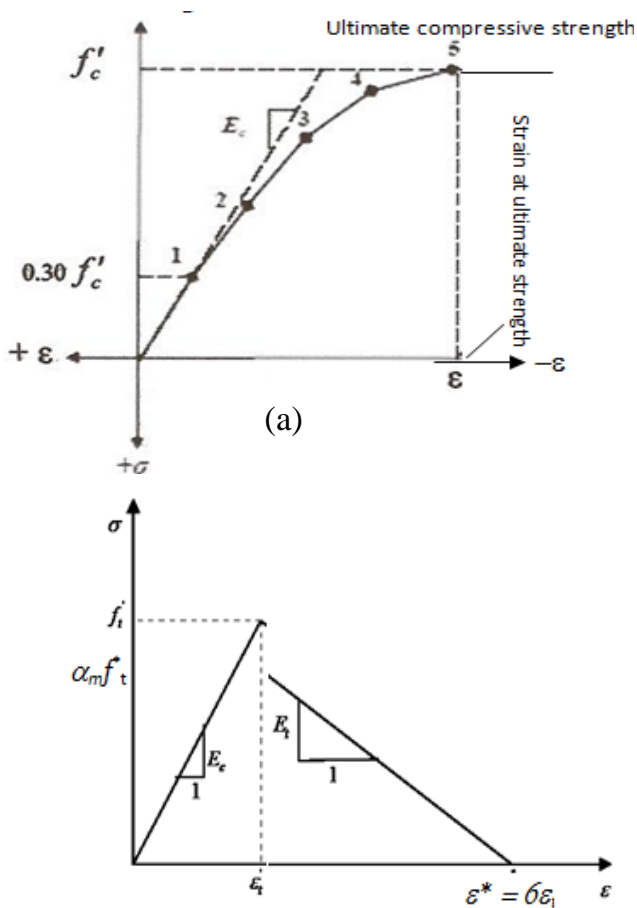

(b)

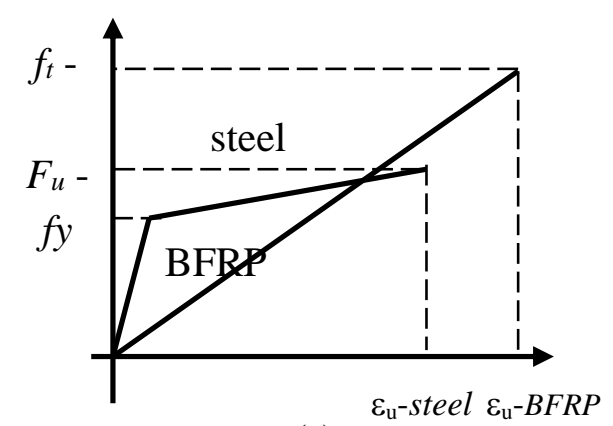

(c)

Fig.3. Material models adopted in the present work (a) For concrete in compression (b) For concrete in tension(c) For BFRP and steel bars.

\subsection{Finite element modelling}

Owing to the symmetry conditions with respect to the $\mathrm{X}$ and Z- axes, only a quarter of each slab was considered to be analysed, as shown in Fig. 4. This may result in increasing the accuracy of results if the same number of elements are used for the full specimen. In addition, the boundary condition, loading condition and supports are depicted. Furthermore, Fig. 5 shows the element utilized to represent the different materials of the tested specimens, which are; 3D Solid element, SOLID65 is utilized to represent concrete and 3D Solid element, SOLID185 is utilized to represent plates at loading points and supports.
Furthermore, the 3D spar element, link180 used to represent steel and basalt bars.

Because that FRP bars, in general, are weak to resist compression comparing with steel bars. Then, link180 that represents such bars is made inactive when being in compression. In this model, a typical node has a translational degree of freedom with respect to each one of the coordinate axes.

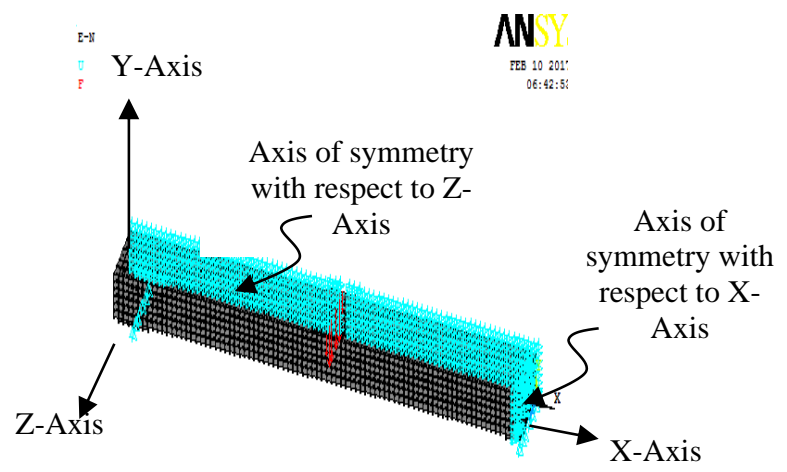

Fig. 4. Finite element discretization for a quarter of a typical specimen

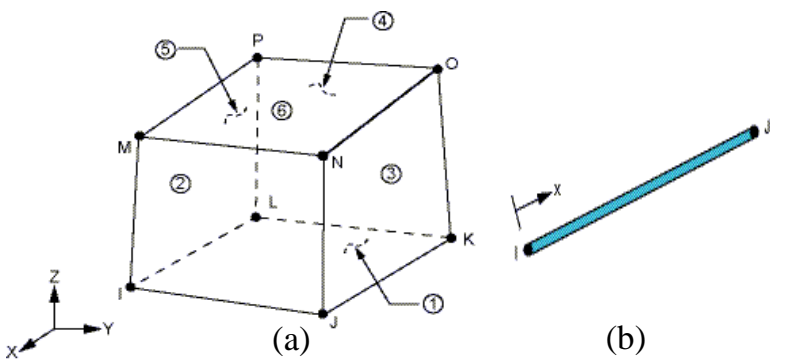

Fig. 5. Element types used in the present work (a) solid 65 and solid 185 (b) link 181

\section{RESULTS AND DISCUSSIONS}

\subsection{Load-deflection results}

As it has been mentioned previously that the behaviour of the slabs considered in the present study has been estimated by Mahroug et al. (2014) using the method of ACI440 committee to compare with the experimental tests. The results for the tested slabs are shown in Fig. 6 to Fig. 11 and Table 3.

It can be easily concluded that the ACI440 equations result in underestimating the value of deflection at failure relative to experimental results with a range of $15 \%-49 \%$ corresponding to an absolute difference of $3 \%-9 \%$ for the results of the present study. The load mid-span deflection records for the specimens SO and SU are shown in Fig. 6 and Fig. 7 respectively. It can be observed that the proposed material models for analysis seem to be efficient enough to simulate the behaviour of simply supported slabs with 
embedded BFRP bars. Corresponding information can be seen with the experimental results of $97 \%$ and $102 \%$ for specimens SU and SO respectively. In contrast, the predicted deflections according to the equation of ACI440 committee showed a stiffer response and some conservative values in the maximum expected deflections of $81 \%$ and $85 \%$ with respect to the experimental results. This refers that the ACI440 equations do not treat or consider the nonlinear behaviour of one-way slabs with BFRP bars effective. Furthermore, the gradual degradation in stiffness due to cracking propagation maybe not included in these equations, whereas it is considered by the ANSYS model by adopting the cracking factor $(\alpha)$.

The loading history for continuous slabs is shown in Fig. 8 to Fig. 11. Fig. 8 shows the response for the specimen $\mathrm{COO}$ in which high ratio of basalt bars are used at sagging and hogging regions. It can be seen that there is corresponding information between the finite element analysis and experimental results. However, a stiffer response has been obtained with a maximum deflection of $81 \%$ when applying the procedure of ACI committee. For specimen SOU, the longitudinal reinforcement at sagging region was reduced from $0.5 \%$ to $0.2 \%$. The loading history is shown in Fig. 9. Again, there is good convergence between the ANSYS model and experimental tests. Whereas ACI440 equations produced a stiffer response and smaller deflection at a failure of about $60 \%$ of that recorded experimentally. The same conclusion can be drawn for specimen SUO where a relatively small amount of basalt bars are used at hogging zone. Results revealed that the finite element and material models proposed in the present study could predict the response of one-way slabs efficiently. Regarding the ACI440 equations, a conservative result can be observed, stiffer response and the predicted deflection at the instant of failure is $77 \%$ of that recorded for the experimental test.

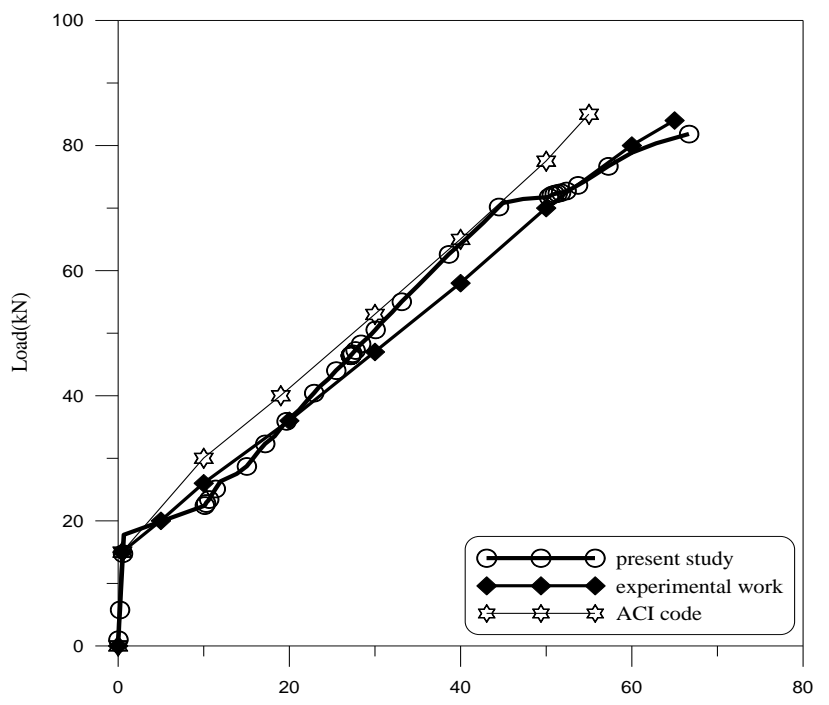

Fig. 7. Load-deflection curves of the slab (SO)
The specimen CUU is reinforced with a small amount of the main reinforcement at both top and bottom faces and the loading history as depicted in Fig.11. It can be noticed that the proposed model in ANSYS yielded a relatively soft response but with the same failure load and maximum deflection at failure. However, the ACI prediction for maximum deflection is found to be $51 \%$ of the corresponding experimental value. From the above discussion, it can be concluded that the numerical and material models of ANSYS can be adopted effectively to simulate and predict the nonlinear response of one-way simply supported slabs reinforced with BFRP bars. Moreover, it can be realized that adopting the ACI440 method yielded a stiffer response. Such stiffness increased for the continuous slabs. The equations of deflection yielded smaller values in the range of $19 \%-49 \%$ of the experiments, and the difference increased by reducing the main reinforcement.

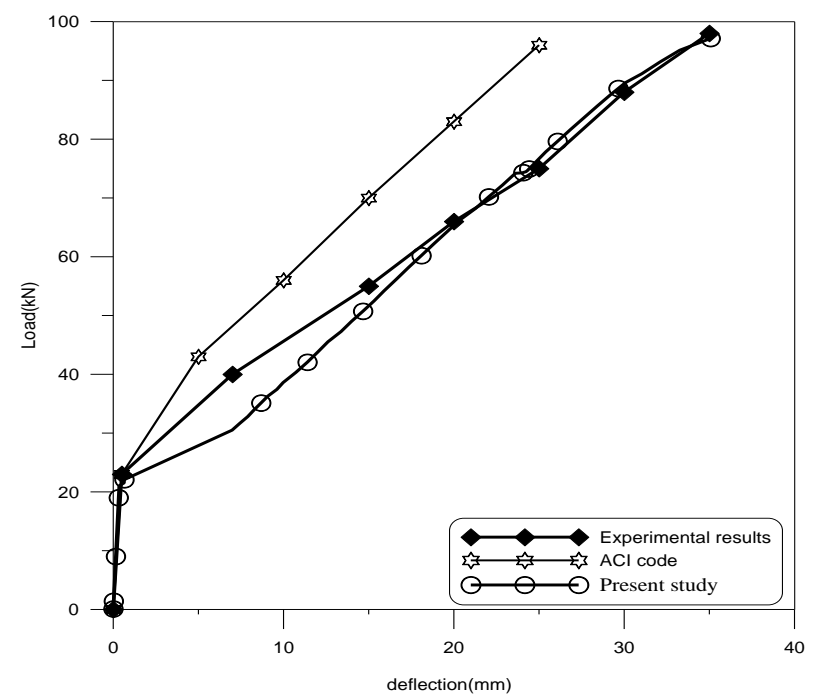

Fig. 8. Load-deflection curves of the slab (COO)

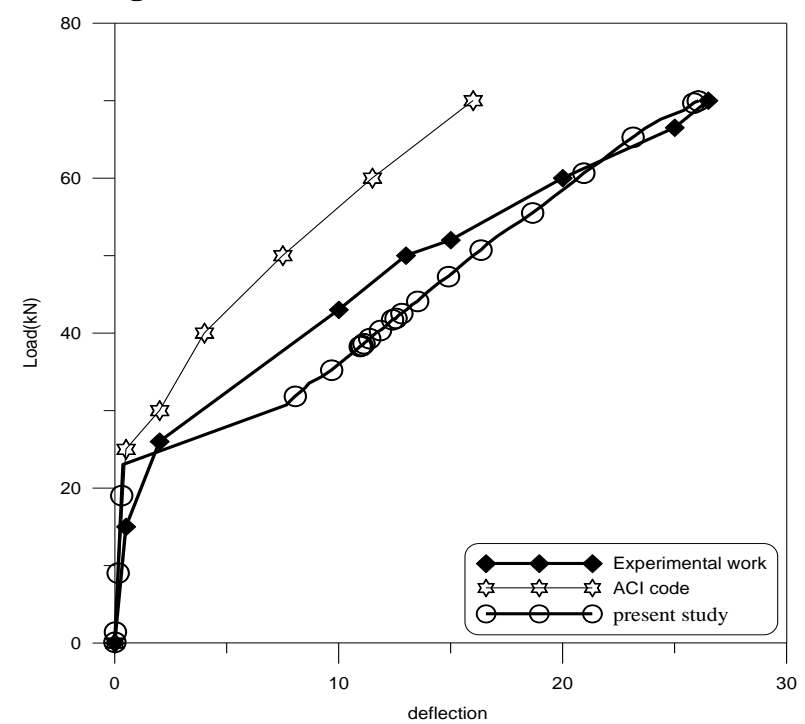

Fig. 9. Load-deflection curves of the slab (COU) 


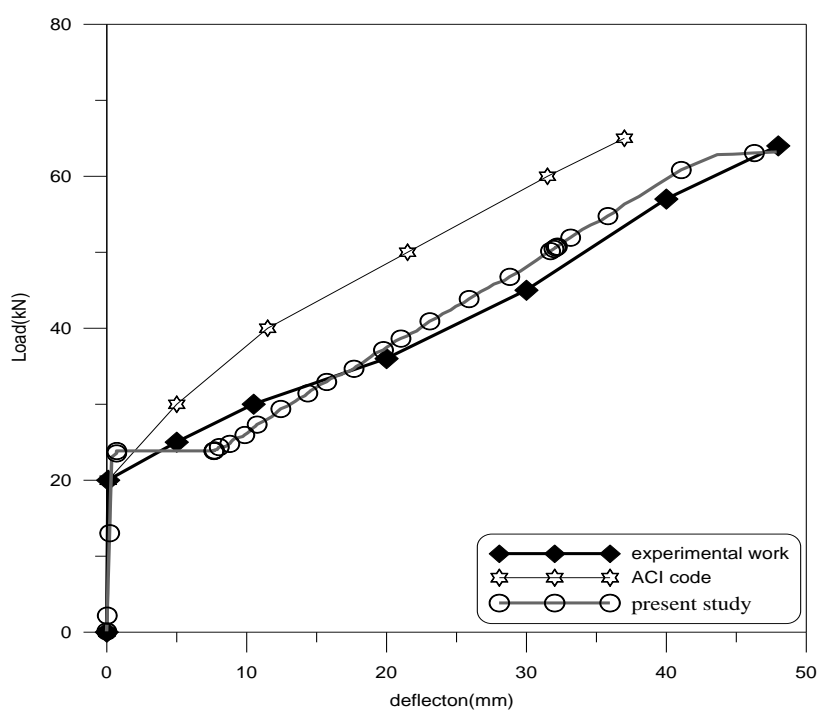

Fig. 10. Load -deflection curves of the slab (CUO)

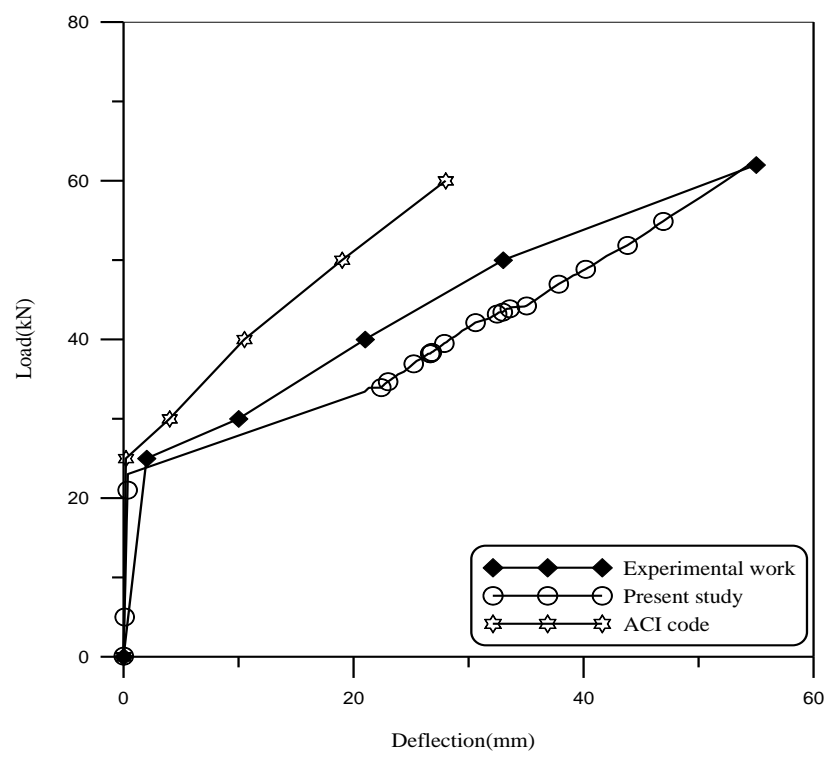

Fig. 11. Load -deflection curves of the slab (CUU)

Table 3 Maximum deflections for the tested slabs ( $\mathrm{mm}$ )

\begin{tabular}{|l|l|l|l|}
\hline Slab & $\boldsymbol{\Delta}_{\exp } *$ & $\begin{array}{l}\text { Present work } \\
\left(\% \boldsymbol{\Delta}_{\exp }\right)\end{array}$ & ACI440 (\% $\left.\boldsymbol{\Delta}_{\exp }\right)$ \\
\hline SU & 66 & $63.88(97 \%)$ & $53.5(81 \%)$ \\
\hline SO & 65 & $66.7(102 \%)$ & $55(85 \%)$ \\
\hline COO & 32 & $35(109 \%)$ & $26(81 \%)$ \\
\hline COU & 26.5 & $26.6(100 \%)$ & $16(60 \%)$ \\
\hline CUO & 48 & $48.4(101 \%)$ & $37(77 \%)$ \\
\hline CUU & 54.3 & $54(99 \%)$ & $28(51 \%)$ \\
\hline
\end{tabular}

* $\Delta_{\text {exp }}$ : Maximum deflection recorded from experimental test

\subsection{Failure loads}

Fig. 12 illustrates the load capacities for the tested specimens. For the simply supported slabs, it can be observed that increasing reinforcement from $0.2 \%$ to $0.5 \%$ resulted in enhancement of capacity by $86 \%$. Regarding continuous slabs, it can be seen that using a high reinforcement ratio at sagging and hogging regions resulted produced the highest failure load. The value of failure load is reduced severely by $38 \%$ when the amount of reinforcement is relatively small and reduced to $0.2 \%$ at top and bottom, specimen CUU. Comparing the ultimate loads of specimens $\mathrm{COU}$ and $\mathrm{CUO}$, it can be observed that with the reinforcement ratio of $0.7 \%$, the arrangement in specimens COU represents the better distribution of longitudinal reinforcement with increment in capacity by $12.5 \%$ and a reduction in maximum deflection $46 \%$ relative to CUO.

It can be concluded that for reinforced concrete continuous slabs and one-way slabs reinforced BFRP bars, a slight improvement in load capacity is noticed when reinforcement ratio is equal or lower than $0.7 \%$ (for CUU and $\mathrm{COU}$ ). Beyond that, a considerable improvement was seen. Therefore, when it is intended to use BFRP bars as reinforcement, it is recommended to adopt reinforcement with ratios higher than $1 \%$.

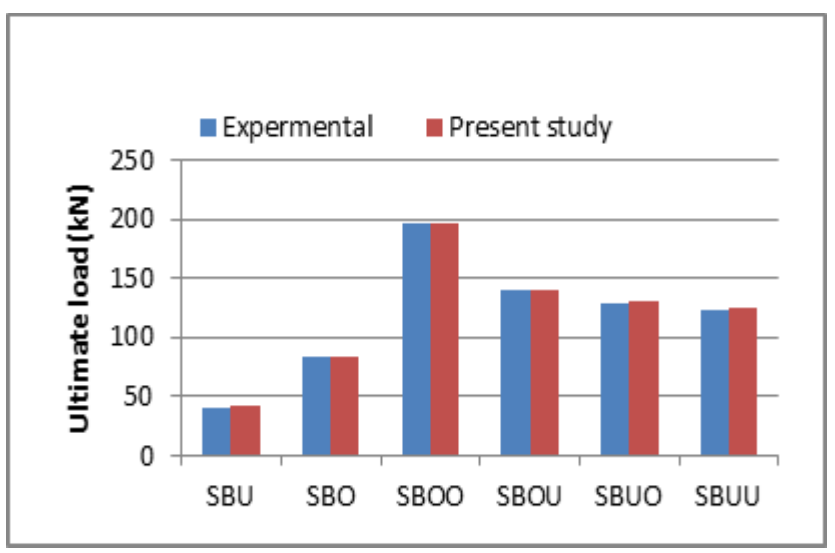

Fig.12. Comparison of the failure load of present work with experimental tests

\subsection{Toughness values}

Fig. 13 shows the toughness values predicted for the tested specimens based on the finite element analysis, ACI440 committee method compared to the experimental tests. It can be seen that the toughness values for the finite element software agree with the values of the experimental tests with a range of difference of $1 \%-15 \%$. It can be concluded that the adopted material models are quite enough to simulate the behaviour of simply supported and continuous slabs with embedded BFRP bars. Regarding the toughness values calculated based on the ACI440 committee, it can be seen that the ACI440 is generally conservative relative to the two other studies. The reduction in toughness values is obtained in the range of $20 \%-50 \%$ relative to experimental tests with higher values of $50 \%$ of specimens with a small area of reinforcement at the interior 
support of specimen CUU. This may be due that basalt bars are stiff to some limit, then fracture occurs suddenly without any warning. For the specimens with a high ratio of reinforcement at hogging region in interior support, the prediction of toughness value is in the range of $64 \%-70 \%$ of the experimental tests. It can be seen that specimen COU yielded a higher capacity than CUO but with less toughness by $45 \%$. for the simply supported slabs, the predicted toughness values for specimens SU and SO have been found to be $101 \%$ and $109 \%$ respectively (based on FEA results). Thus, it is recommended to use high reinforcement content on both top and bottom faces (specimen CUU). Thus, it can be concluded the ACI400 is more conservative with continuous one-way slabs with lightly reinforced section sagging regions.

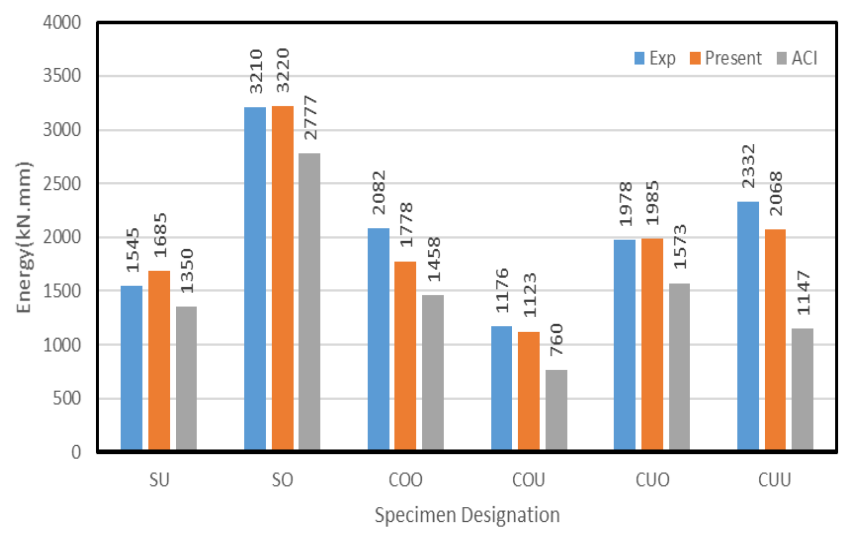

Fig.13. Toughness values for the present work against ACI440 and experimental tests

\subsection{Parametric study}

The continuous slab COO has been chosen to conduct the parametric study, the BFRP bars have been replaced gradually with steel bars, and the slab is analysed.

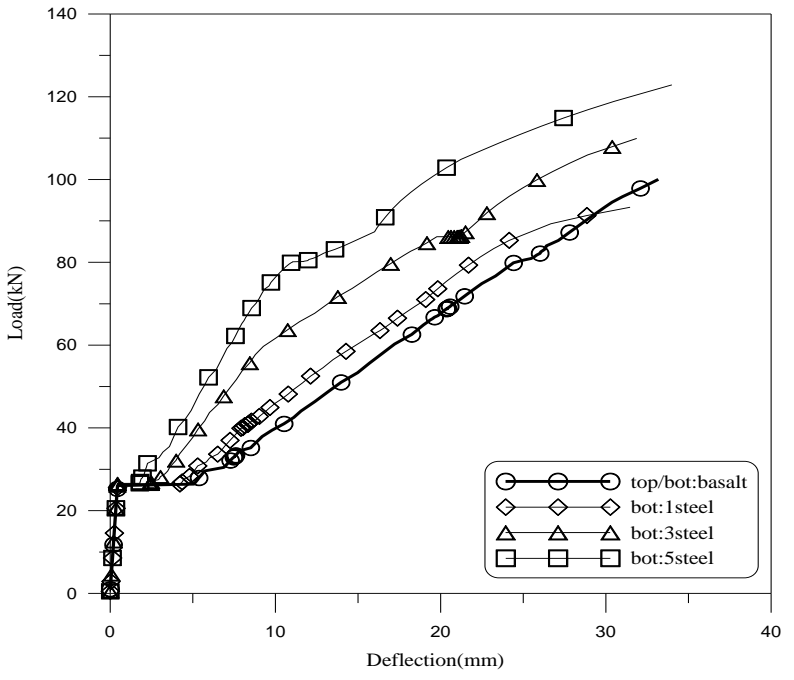

Fig. 14. Replacing the bottom BFRP bars by steel bars

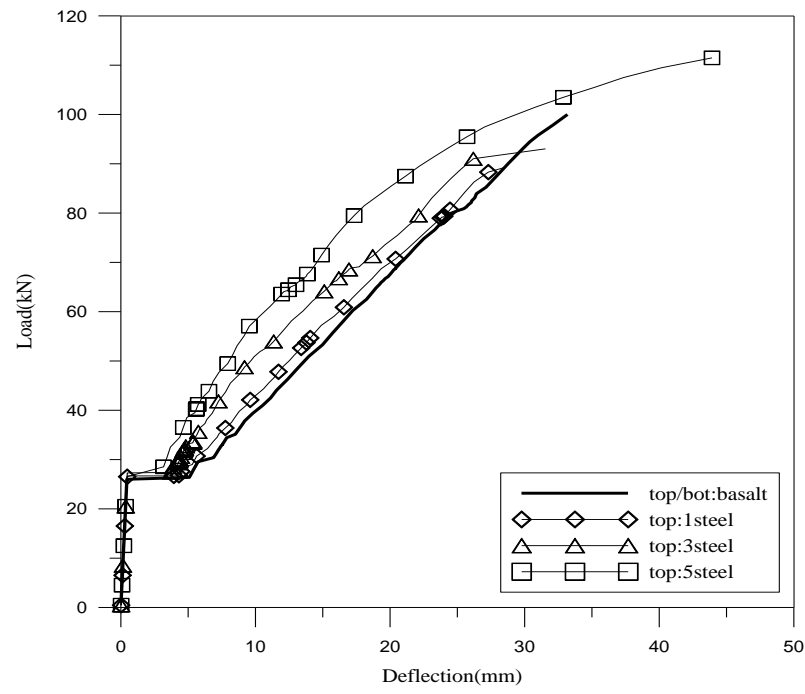

Fig.15. Replacing the top BFRP bars by steel bars

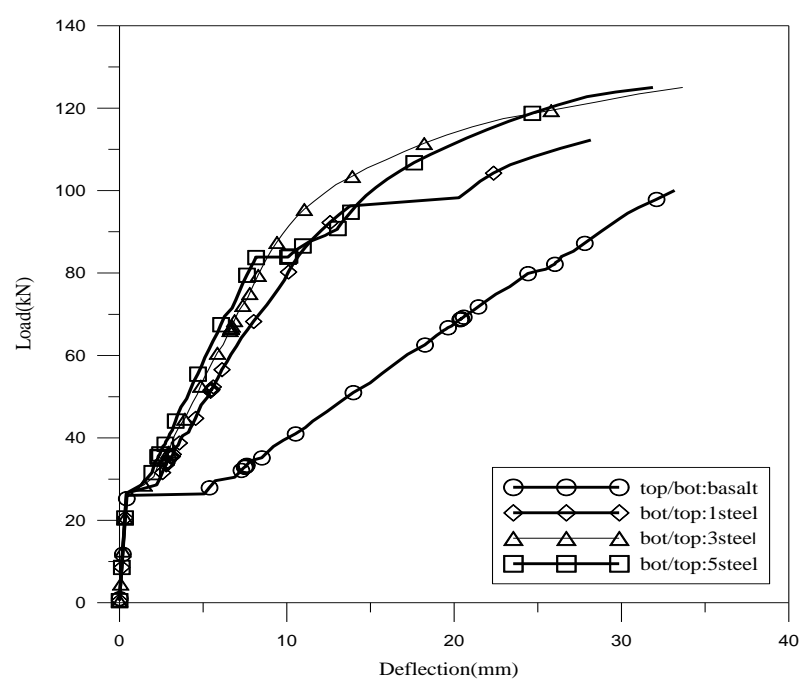

Fig. 16. Replacing the top and bottom BFRP by steel bars

Fig. 14 shows the load-deflection curves when replacing one, three and five BFRP bars at the bottom face with steel bars while keeping the basalts bars at the top face. Fig. 15 shows the effect of changing the basalt bars at the top face with steel bars with keeping the bottom bars without replacement. Fig. 16 shows the variation of response of the slab when replacing both the top and bottom basalt bars by steel bars simultaneously, i.e. one top/one bottom, three top/three bottom, five top/five bottom. It can be seen that replacing the bottom bars yield better results than replacing the top bars. Higher toughness values may be obtained, safety of the slab is enhanced, and failure may be shifted to be ductile rather being of the brittle type. Stiffness of the slab increased gradually, and the capacity increased by $22 \%$ when replacing bottom bars by steel bars. Also, the replacement of both top and bottom bars results in better response than the replacement of bottom bars only. This behaviour can be recognised easily by remembering that 
bottom reinforcement effects on the mid-span of two spans, while the top reinforcement affects the portion at interior support only.

When replacing the top bars, it can be seen that there is no significant improvement in response, a slight increase in failure load of $10 \%$. This may be attributed that steel bars have better resistance to compressive stresses compared with BFRP bars and that BFRP bars are inactive to resist high curvature. Note that Fig. 14 to Fig. 16 are outlined for one half of the continuous beam $\mathrm{COO}$.

\section{CONCLUSIONS}

1- The ACI code results have found to be more acceptable to predict the behaviour of simply supported slabs, especially for over reinforced slab sections, and less convergence with experiments for slabs with underreinforced sections with maximum divergence for the under-reinforced specimens.

2- It is found with an efficient distribution of bars (changing from $\mathrm{CUO}$ to $\mathrm{COU}$ ) that for a slab with reinforcement ratio of $0.7 \%$, the load capacity is improved by $12.5 \%$ and a reduction in maximum deflection $46 \%$. While the load capacity is improved by $61 \%$ when adopting a ratio of $1 \%$ while the maximum deflection is reduced by $56 \%$.

3- For reinforced concrete continuous slabs and one-way slabs reinforced BFRP bars, a slight improvement in load capacity is noticed when reinforcement ratio is lower than $0.7 \%$. Beyond that, a considerable enhancement was seen. Therefore, when it is intended to use BFRP bars as reinforcement, it is recommended to adopt over reinforced sections.

4- The nonlinear model adopted in the present investigation agrees with the experiment test for simply supported specimens. For continuous slabs, it is found that there is some divergence of the experimental results in some stages beyond the first crack.

5- It is found that the predicted dissipated energy for the tested specimens using the FEA and differs by $1 \%-15 \%$ relative to the experimental results. Whereas, the ACI440 equations showed a difference of $20 \%-50 \%$. This revealed that the ACI440 equations generated stiffer and very conservative results.

\section{Notation}

$f_{c}$ : Concrete stress corresponding to strain $\varepsilon,(\mathrm{MPa})$.

$\varepsilon_{1}$ : Concrete strain at cracking (end of elastic stage).

$\varepsilon_{0}$ : Strain at the end of elastic-plastic stage (at $f^{\prime} c$ ).

$\varepsilon_{u}$ : Strain at failure.

$E_{c}$ : Modulus of elasticity of concrete, $(\mathrm{MPa})$

$\alpha_{m}$ : Tension stiffening factor

$f_{t}$ : Tensile strength of concrete $f_{y}$ : Yield stress of steel

$f_{c u}$ : Cube compressive strength of concrete

$f_{u}$ : Ultimate strength of steel or BFRP bars

Specimen designation is either $S_{1} S_{2}$ (for simple spans) or

$\mathrm{S}_{1} \mathrm{~S}_{2} \mathrm{~S}_{3}$ (for continuous spans);

S1: Simple span (S) or continuous (C)

$\mathrm{S} 2$ : Reinforcement ratio at bottom face (U: $0.2 \%$ or O:

$0.5 \%$ )

S3: Reinforcement ratio at top face (U: $0.2 \%$ or O: $0.5 \%$ )

\section{REFERENCES}

[1] Issa, M. A., Ovitigala, T., \& Ibrahim, M. (2016). Shear behavior of basalt fiber reinforced concrete beams with and without basalt FRP stirrups. Journal of Composites for Construction, 20(4),1-11.

[2] Marlena, R., \& Bartłomiej, S. (2014). Reinforcement of prefabricate concrete beams with basalt-epoxy bars. Advanced Materials Research, 1020, 275-279.

[3] Meng, W., Liu, H., Liu, G., Kong, X., \& Wang, X. (2016). Bond-slip constitutive relation between bfrp bar and basalt fiber recycled-aggregate concrete. KSCE Journal of Civil Engineering, 20(5), 1996-2006.

[4] Ramakrtshnan, V., \& Panchalan, R. K. (2003). Performance characteristics of basalt rebar reinforced concrete beams. Proc. Int. Symp., Brittle Material 7, Woodhead publishing, Cambridge, England, 553-560.

[5] El Refai, A., Ammar, M. A., \& Masmoudi, R. (2015). Bond performance of basalt fiber-reinforced polymer bars to concrete, Journal of Composites for Construction ,19(3), 1-12.

[6] Ge, W., Zhang, J., Cao, D., \& Tu, Y. (2015). Flexural behaviors of hybrid concrete beams reinforced with bfrp bars and steel bars. Construction and Building Materials, 87(2015), 28-37.

[7] Neela, S. (2010). Flexural behavior of basalt frp bar reinforced concrete members with and without polypropylene fiber. M.Sc. thesis dissertation, University of Akron, Ohio city, USA.

[8] Ashraf, F. (2014). Behaviour of continuous concrete slabs reinforced with FRP bars. Experimental and computational investigations on the use of basalt and carbon fibre reinforced polymer bars in continuous concrete slabs. Ph.D. thesis dissertation, University of Bradford, Bradford, England.

[9] Mahroug, M. E. M., Ashour, A. F., \& Lam, D. (2014). Experimental response and code modelling of continuous concrete slabs reinforced with BFRP bars, Composite Structures, 107(2014), 664-674.

[10] Elgabbas, F. M. (2016). Development and structural testing of new basalt fiber-reinforced-polymer (BFRP) bars in RC beams and bridge-deck slabs". Ph.D. thesis dissertation, Sherbrooke, Québec, Canada. pp. 259.

[11] Akiel, M. S. (2016). Performance of continuous concrete slabs reinforced with hybrid steel-basalt bars. 
Thesis dissertation, United Arab Emirates University, Abu Dhabi, UAE, pp. 459.

[12] Zhou, L., Zheng, Y., \& Taylor, S. (2018). Finiteelement investigation of the structural behavior of basalt fiber reinforced polymer (BFRP)- reinforced self-compacting concrete (scc) decks slabs in thompson bridge. Polymers, 10(678), 1 - 23.

[13] Rihan, Y. A. O. (2018). Flexural behavior of basalt fiber reinforced one-way concrete slabs reinforced with fiber reinforced polymer bars. M.Sc. thesis dissertation, Qatar University, Doha, Qatar.

[14] Attia, K., Alnahhal, W., Elrefai, A., \& Rihan, Y.A.O., (2019). Flexural behavior of basalt fiber-reinforced concrete slab strips reinforced with BFRP and GFRP bars. Composite Structures, 211(2019), 1-12.

[15] SAS ANSYS 15 (2013). Finite element system software. SAS, IP, Inc., USA.

[16] Kumar, M., Ma, Z., \& Matovu, M. M. (2012). Report on the mechanical properties of high-strength concrete, University at Buffalo, State University of New York, New York, USA.

[17] Wolanski, A. J. (2004). Flexural behavior of reinforced and prestressed concrete beams using finite element analysis. M.Sc. thesis dissertation, Marquette University Milwaukee, Wisconsin, USA. 